\title{
The Relationship Between Oxidation and Thermal Fatigue of Martensitic Hot-Work Die Steels
}

\author{
Qi-Chuan Jiang ${ }^{1} \cdot$ Xu-Min Zhao ${ }^{1} \cdot$ Feng Qiu $^{1} \cdot$ Tian-Ning Ma $^{2} \cdot$ Qing-Long Zhao $^{1}$
}

Received: 22 November 2017/Revised: 14 December 2017 / Published online: 28 December 2017

(C) The Chinese Society for Metals and Springer-Verlag GmbH Germany, part of Springer Nature 2017

\begin{abstract}
Thermal fatigue behaviors of two forged hot-work die steels subjected to cyclic heating $\left(650{ }^{\circ} \mathrm{C}\right)$-water quenching were investigated. A martensitic hot-work die steel containing 10\% $\mathrm{Cr}$ (HHD), showing superior oxidation resistance and thermal fatigue resistance to the commercial martensitic hot-work die steel (Uddeholm DIEVAR ${ }^{\circledR}$ ), was developed. The maximal crack length in HHD was 35\% shorter than that in DIEVAR after 2000 thermal cycles, and the hot yield strength at $650{ }^{\circ} \mathrm{C}$ of $\mathrm{HHD}$ was $14 \%$ lower than that of DIEVAR prior to thermal fatigue testing, which is $30 \%$ higher after 1500 cycles. It is found that cracks initiated and propagated along the oxide layers in the grain boundaries, suggesting that the oxidation-induced thermal fatigue cracks can significantly reduce the mechanical performance and service life for the hotwork die steel. High-temperature oxidation behavior is crucial for thermal fatigue crack formation, while high-temperature yield strength and ductility play a less important role.
\end{abstract}

Keywords High-temperature oxidation - Crack initiation and propagation $\cdot$ Strength and plasticity $\cdot$ Thermal fatigue resistance . Tool steel

\section{Introduction}

Crack initiation and propagation induced during thermal fatigue as the main life-limiting failure mechanism of diecasting dies [1-4] is responsible for $70 \%$ of the failures in die casting [5]. The temperature on cavity surface achieves $\sim 853 \mathrm{~K}$ in the die-casting process of $\mathrm{Al}$ alloy, while the highest temperature is $\sim 1099 \mathrm{~K}$ for copper alloy die casting [6]. Under such service conditions, the service life of dies was reduced [7, 8]. A model proposed by Malm and Norström [9] suggested that the initiation and propagation

Available online at http://link.springer.com/journal/40195

Electronic supplementary material The online version of this article (https://doi.org/10.1007/s40195-017-0699-8) contains supplementary material, which is available to authorized users.

Qing-Long Zhao

zhaoqinglong@jlu.edu.cn

1 Key Laboratory of Automobile Materials, Ministry of Education, College of Materials Science and Engineering, Jilin University, Changchun 130025, China

2 Jiangsu Jin Gang Special Steel Co., Ltd, Danyang 212314, China of thermal fatigue cracks were mainly influenced by the thermophysical properties (e.g., thermal expansion coefficient and elasticity modulus) and the yield strength of the tool steel, and the prediction of the model was well consistent with the experimental facts that high yield strength at high temperature and good temper resistance increased thermal fatigue resistance [10]. Their model has been widely adopted in the literature $[5,11]$. It was also suggested that good ductility and toughness became important to fatigue resistance when subjected to high strain amplitudes [12] or reduced maximal temperature during thermal cyclic tests [13]. Previous researches have focused on increasing the mechanical properties of the steels at ambient and high temperatures via precipitation strengthening of carbides (such as $\mathrm{NbC}$ and $\mathrm{M}_{23} \mathrm{C}_{6}$ ) by alloying and heat treatments [14-16]. Reduced $\mathrm{C}$ content and increased $\mathrm{Cr}$ and Mo contents in hot-work die steel, with an addition of alloying elements such as $\mathrm{Nb}$ and $\mathrm{V}$, can stabilize martensite laths at high temperature and induce fine precipitates, leading to improvement in thermal fatigue resistance [3, 17-19]. It is reported that the nitrogen addition could increase the hardness and tempering resistance of 4Cr5Mo2V Hot-Working Die Steel [20]. A small addition of rare earth elements can refine the grain size and eutectic 
carbides, leading to the increases of impact toughness, tensile properties and thermal fatigue resistance of $\mathrm{Cr}-\mathrm{Ni}-$ Mo [21] and 4Cr5MoSiV1 [22] hot-work die steels. The addition of Boron to $3 \mathrm{Cr} 10 \mathrm{Mn} 7 \mathrm{Ni} 6 \mathrm{SiCu}$ steel can increase hardness by $100 \mathrm{HV}$, tensile yield strength at $850{ }^{\circ} \mathrm{C}$ from 144.3 to $190.3 \mathrm{MPa}$, and its thermal fatigue (273-1073 K) was rated as grade $2-3$, which was greatly superior to rating grade $7-8$ of $\mathrm{H} 13$ hot-work die steel [23]. The optimization of heat treatments such as austenitizing and tempering was also attempted to improve high-temperature stability, strength and toughness of the steel [13, 24]. Heat treatments were designed to optimize the austenitic grain size, solute content and precipitation [25], increasing hardness and impact toughness [26]. It is reported that proper quenching-partitioning-tempering treatment could improve the fatigue resistance of $20 \mathrm{Mn} 2 \mathrm{SiCrNiMo}$ bainite/martensite multiphase steels due to the presence of leaf-shaped bainite and refined retained austenite [27]. In recent years, surface engineering such as physical vapor deposition (PVD) and gas nitriding have been widely applied to die-casting dies as a new treatment. It could induce high residual compressive stress on the surface and increase surface hardness, leading to the increase in the threshold of crack initiation [4, 5]. However, surface coating is brittle and might not effectively suppress the propagation of cracks into the substrate material [4].

However, the above improvements are still unsatisfactory to meet the development trend of large-scale and highprecision hot-work dies. The formation mechanism of thermal fatigue cracks and its dominant factors have not been thoroughly understood. Besides the mechanical properties of die steel, the environmental effect like oxidation also strongly influences thermal fatigue life. Previous researches suggested that the crack initiation was caused by the accumulation of local plastic strain on the surface, and the oxidation of the cracked surface induced tension stress in the crack tip due to the larger specific volume of oxide, promoting crack growth [1, 2, 28, 29]. It is reported that grain boundary oxidation in a superalloy accelerated fatigue crack growth at $650-700{ }^{\circ} \mathrm{C}$ [30]. However, the influence of oxidation resistance on thermal fatigue of hot-work die steels is not fully understood. The present work is to explore the role of oxidation in the formation of thermal fatigue cracks. We developed a new chemical composition design of the alloy containing $10 \%$ $\mathrm{Cr}$, which differed from the generally accepted composition design $(\leq 5 \% \mathrm{Cr})$ of commercial hot-work die steels, trying to increase the oxidation resistance and thermal fatigue resistance of the alloy.

\section{Materials and Methods}

The chemical composition of experimental material is shown in Table 1. The high $\mathrm{Cr}$ martensitic hot-work die steel (HHD) developed was produced by Jiangsu Jin Gang Special Steel (China). DIEVAR is a premium hot-work die steel produced by Uddeholm (Sweden), which exhibits increased temper resistance and superior resistance to various die failures, compared to typical H13 steel (e.g., ASSAB 8407) and premium H13 steel (e.g., ASSAB 8407 Supreme). The experimental materials were supplied in hot-forged condition. After austenitizing treatment, quenching and twice tempering, the hardness of HHD was 50.8 HRC, similar to DIEVAR (50.3 HRC).

The heating-cooling cyclic test was performed by heating the specimens to $923 \mathrm{~K}$ in a resistance furnace and quenching in water, using an in-house equipment. The equipment schematic and the geometry of the specimens are illustrated in the supplement (Fig. S1 and Fig. S2). Heating per cycle took $180 \mathrm{~s}$ and water quenching per cycle took $20 \mathrm{~s}$. The specimens for crack observation were $50 \mathrm{~mm} \times 20 \mathrm{~mm} \times 5 \mathrm{~mm}$ with a U-notch of $6 \mathrm{~mm}$ long and $0.18 \mathrm{~mm}$ wide at the end of the specimen. The tensile specimens were $2.5 \mathrm{~mm}$ wide and $2 \mathrm{~mm}$ thick with a gauge length of $10 \mathrm{~mm}$ shown in the supplement (Fig. S3). The tensile specimens subjected to thermal cyclic test were tensile tested without mechanical polishing of surface oxide at a strain rate of $\sim 10^{-4} \mathrm{~s}^{-1}$ using hydraulic testing machines (MTS 810 for room temperature testing and RDL50 for high-temperature testing). Tensile testing at $923 \mathrm{~K}$ was performed by heating the tensile specimens to $923 \mathrm{~K}$ with a heating rate of $\sim 15-20 \mathrm{~K} / \mathrm{min}$ and then holding for $10 \mathrm{~min}$ prior to testing under Ar atmosphere. The initiation and propagation of fatigue cracks and oxide layers were observed by a scanning electron microscope (SEM) Zeiss Evo18 equipped with energy disperse spectroscopy (EDS). Thermal fatigue grade was assessed according to GB/T 15824-2008 (thermal fatigue testing method for hot die steel, China). The surface was mechanically polished to remove the oxide layer for hardness test and SEM observation.

Table 1 Chemical composition (wt \%) of the HHD and the DIEVAR steel

\begin{tabular}{lrllllll}
\hline & $\mathrm{Cr}$ & $\mathrm{C}$ & $\mathrm{Si}$ & $\mathrm{Mn}$ & $\mathrm{P}$ & $\mathrm{Mo}$ & $\mathrm{V}$ \\
\hline HHD & 10.26 & 0.29 & 0.85 & 0.25 & 0.02 & 1.87 & 0.77 \\
DIEVAR & 4.91 & 0.37 & 0.07 & 0.37 & 0.01 & 2.24 & 0.46 \\
\hline
\end{tabular}




\section{Results}

\subsection{Thermal Fatigue}

Figure 1 shows the formation of oxide layers after thermal fatigue test and their propagation into the interior of matrix. The oxidation of DIEVAR was obviously severer than that of HHD after 500-2000 thermal cycles (Fig. 1). At the end of notch, the shedding of oxide layer was observed in DIEVAR after 1000 thermal cycles (Fig. 1f). The oxide layers developed to a network along the grain boundaries in DIEVAR after 1500 thermal cycles. However, the oxide layers in HHD were relatively straight and less in number. It is found that cracks appeared only in the oxide layers, as indicated by the arrows in Fig. 1.

Figure 2 shows that the maximal crack length increased with increased thermal cycles, and the maximal crack length for HHD was much smaller than that for DIEVAR. After 2000 thermal cycles, the maximal crack length for DIEVAR was $230.4 \mu \mathrm{m}, 54 \%$ longer than that for HHD $(150.0 \mu \mathrm{m})$. The thermal fatigue of DIEVAR was rated as grade 6-7, while the thermal fatigue of HHD was rated as grade 1 . The average crack growth rate for DIEVAR was higher than that for HHD within the range of tests. Within 1500-2000 thermal cycles, the mean growth rate of maximal crack for DIEVAR steel was $0.125 \mu \mathrm{m} /$ cycle, $81 \%$ higher than that for HHD $(0.069 \mu \mathrm{m} /$ cycle $)$. Therefore, HHD steel exhibits superior thermal fatigue resistance than DIEVAR steel.

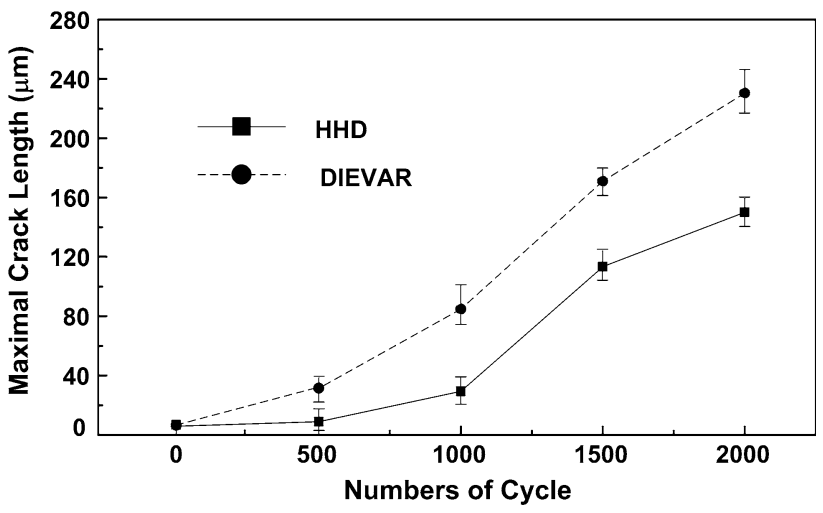

Fig. 2 Maximal crack lengths for both HHD and DIEVAR steels after 500-2000 thermal cycles

\subsection{Mechanical Strength After Thermal Fatigue Testing}

Figure $3 \mathrm{a}, \mathrm{b}$ shows that the maximal length and width of oxide layers for DIEVAR are significantly larger than those for HHD. Meanwhile, DIEVAR contained more oxide cracks than HHD (Fig. 3c). Thus, HHD exhibited stronger oxidation resistance than DIEVAR steel. The length of oxide region was several times longer than the crack length $[1,2]$. The present results indicate that cracks were all initiated in oxide region. Oxidation severely affected the mechanical performance of the samples after thermal cycles. The hardness of matrix steel decreased slightly with the increase of the thermal cycles as shown in Fig. 3d. The
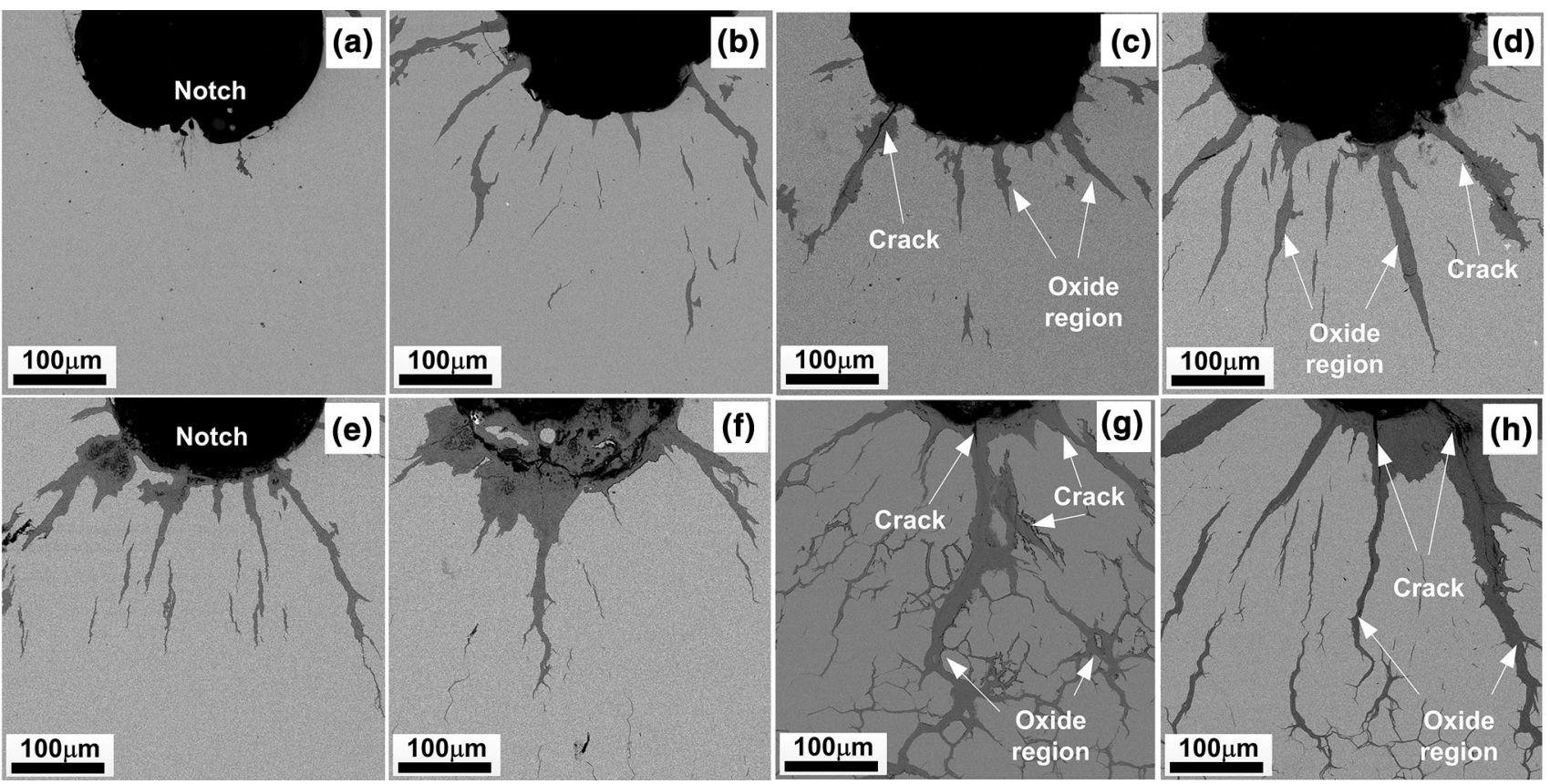

Fig. 1 Oxidation and crack morphologies of two types of hot-work die steel after thermal fatigue $500 \mathbf{a}, \mathbf{e}, 1000 \mathbf{b}, \mathbf{f}, 1500 \mathbf{c}, \mathbf{g} 2000 \mathbf{d}, \mathbf{h}$ cycles: a-d HHD, e-h DIEVAR 

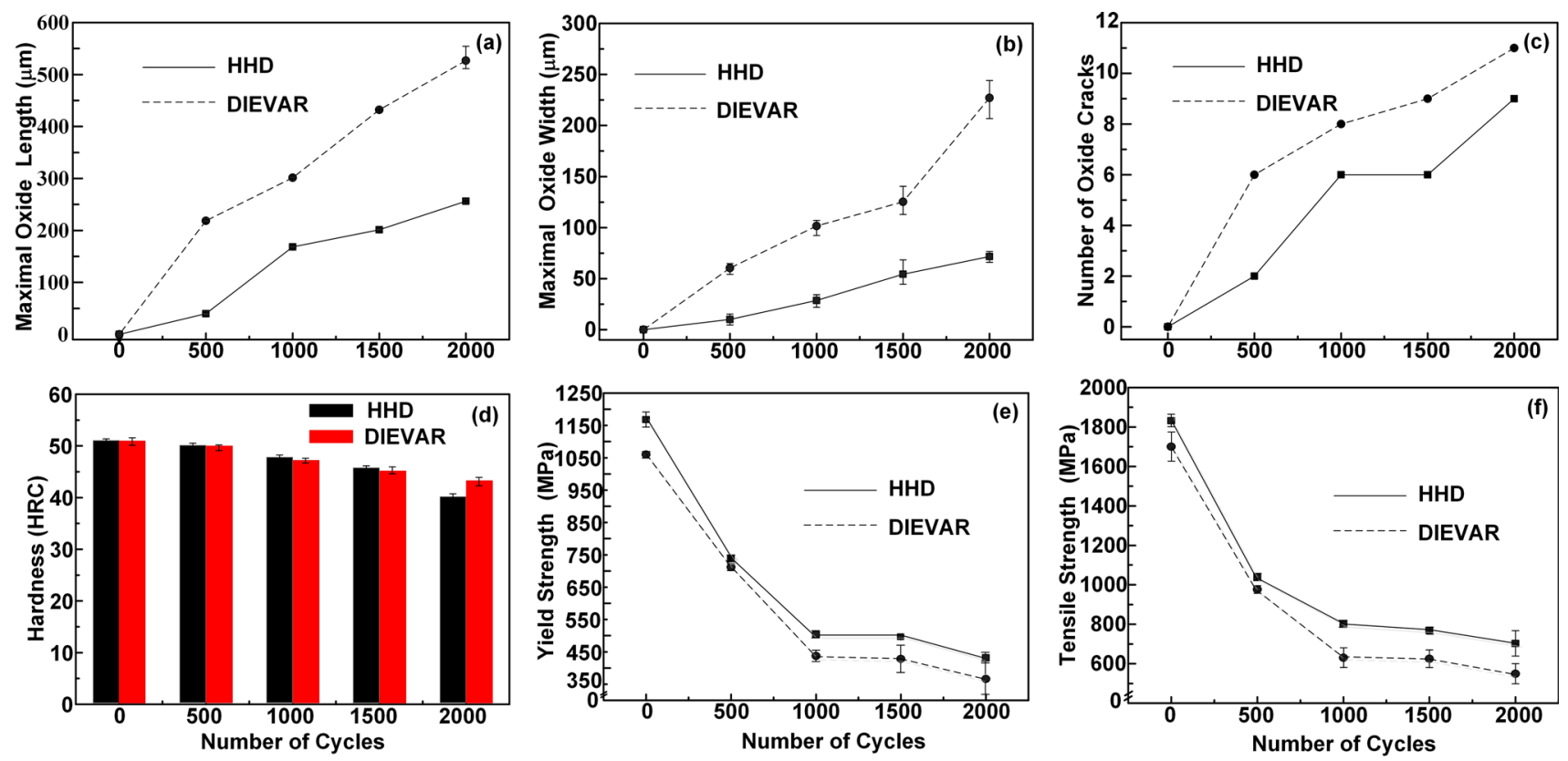

Fig. 3 HHD steel and DIEVAR steel completed 500, 1000, 1500 and 2000 thermal fatigue cycles; a maximal oxide length; b maximal oxide width; $\mathbf{c}$ number of oxide cracks; $\mathbf{d}$ matrix hardness; e yield strength; $\mathbf{f}$ tensile strength

hardnesses of DIEVAR and HHD remained similar after $500-1500$ cycles. After 2000 cycles, the hardness of HHD is a bit lower than DIEVAR, implying that DIEVAR is more resistant to temper softening. However, the mechanical strength at room temperature dramatically decreased after thermal cycles, and the decrease in the strength of DIEVAR is more significant (Fig. 3e, f). After 1500 cycles, the yield strength of HHD at room temperature is $68 \mathrm{MPa}$ higher than that of DIEVAR, while the tensile strength of HHD is 144 MPa higher than DIEVAR. On the other hand, the yield and tensile strength at $923 \mathrm{~K}$ (306 and $402 \mathrm{MPa}$ ) of HHD are lower than those (355 and $504 \mathrm{MPa})$ of DIEVAR prior to thermal fatigue testing. However, the high-temperature yield and tensile strength (273 and $353 \mathrm{MPa}$ ) of HHD become higher than those (209 and $277 \mathrm{MPa}$ ) of DIEVAR steel after 1500 thermal cycles. The elongation after fracture of HHD is a bit higher $(\sim 3 \%)$ than DIEVAR before and after thermal cycles.

\section{Discussion}

Previous researches generally showed that the high yield strength and temper resistance at high temperatures improved the thermal fatigues resistance $[9,10]$. However, the present study contrasts sharply with the general opinion. The yield and tensile strength at $923 \mathrm{~K}$ of DIEVAR prior to thermal fatigue testing are 355 and $504 \mathrm{MPa}$, respectively, which are higher than those of HHD (306 and $402 \mathrm{MPa}$ ). After 2000 cycles, the hardnesses of DIEVAR and HHD as shown in Fig. 3d were 42.9 HRC and 39.9 HRC, respectively, implying that DIEVAR was more resistant to temper softening. However, DIEVAR exhibits lower thermal fatigue resistance and mechanical performance after thermal cycles despite its higher yield strength at high temperatures and better temper resistance. The dramatic decrease in the mechanical strength should be attributed to grain boundary oxidation and the formation of the cracks after thermal cyclic testing. Figure 4 shows the oxidation of the surfaces of the tensile samples. The thickness of the oxide layer reaches $17.0 \mu \mathrm{m}$ for HHD and $45.1 \mu \mathrm{m}$ for DIEVAR after 1000 thermal fatigue cycles. The thinner oxide layer for HHD confirms that the oxidation resistance of HHD is superior to DIEVAR. The EDS line scanning (Fig. 4a) suggests that the oxidized surface of HHD steel is composed of iron oxides mainly, but the inner layer contained a fraction of chromium oxides with a thickness of $\sim 9.3 \mu \mathrm{m}$. The composition of the oxide layer for DIEVAR steel is more uniform, and no Cr-rich layer is observed (Fig. 4b). The iron oxide layer for DIEVAR is fragile, and the oxide layers are easily stripped (Fig. 4b). The higher $\mathrm{Cr}$ content could increase the oxidation and corrosion resistance [31]. Thus, HHD exhibits superior oxidation resistance to DIEVAR.

Figure 5 demonstrates that oxidation cracks propagated from the surface into the steel matrix after 1000 thermal cycles. The EDS line scanning of HHD across the crack (Fig. 5a) indicates that the oxide layer is a mixture of iron and chromium oxides. Cr-rich layers are formed on both sides of the oxidation crack for HHD. The formation of 


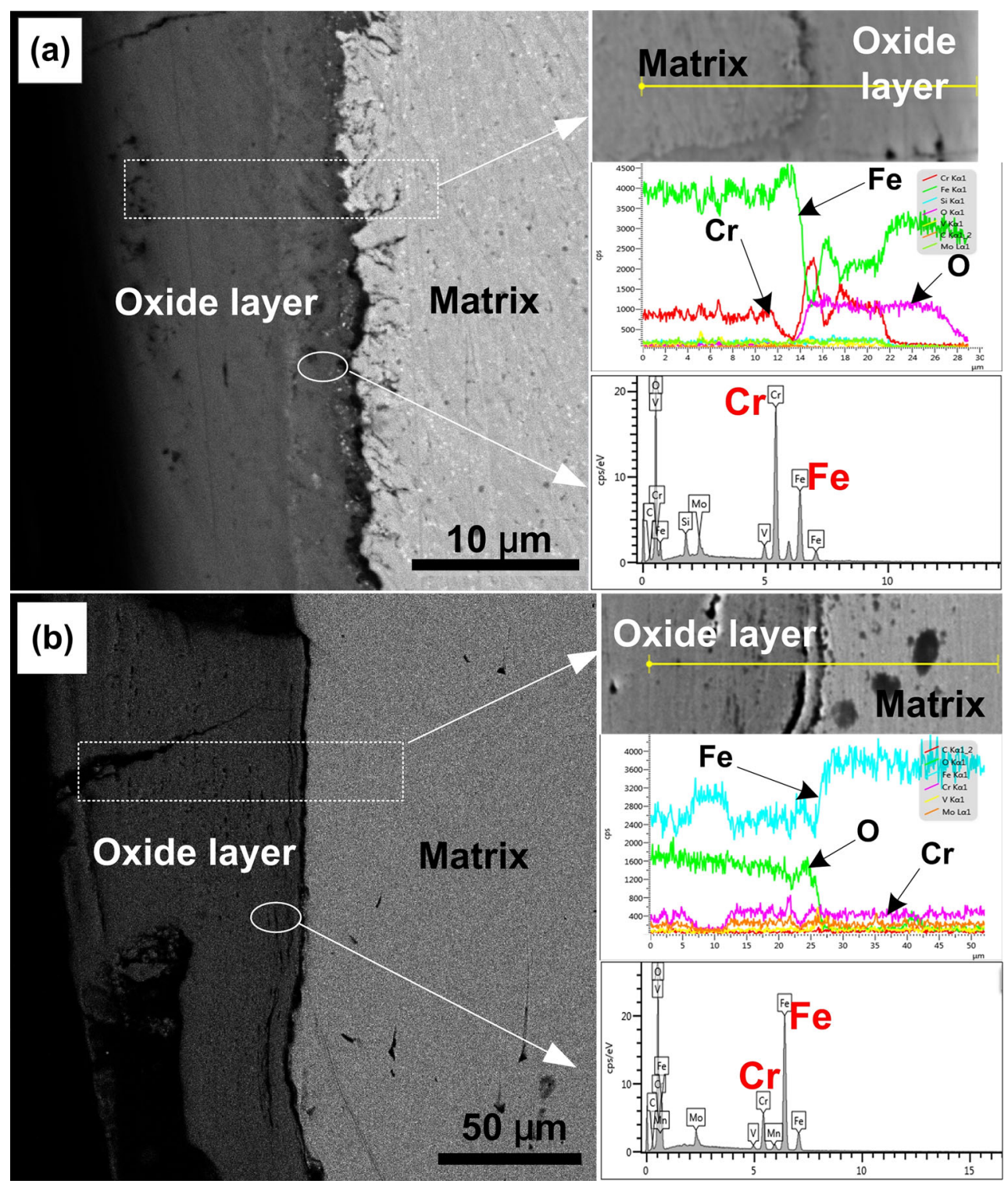

Fig. 4 SEM (backscattered electron) images and EDS spectra of the oxide layer after 1000 cycles: a HHD; b DIEVAR

chromium oxides could effectively retard further oxidation of the steel matrix. Meanwhile, no Cr-rich layer was observed for DIEVAR, and hence, the oxidation region is much longer in DIEVR than in HHD. The crack initiated in the oxide layer and propagated along the oxide layer. It is reported that the thermal mismatch stress and fragility of the oxide layer promote crack propagation [1, 2]. The diffusion of oxygen into the grain boundaries leads to the formation of brittle oxides [30]. These brittle oxides are prone to cracks under local thermal stress. Thus, the mechanical performance of HHD after thermal fatigue is better than that of DIEVAR.

The thermal fatigue crack (heat checking) usually appeared on the surface of die steel as a network of small cracks. During cyclic heating-cooling of the die, a high compressive-tensile stress is produced on the die surface. It is widely accepted that the micro-cracks firstly initiated when the local thermal stress exceeds the local yield strength of the die steel [1, 2, 4, 5]. It was generally believed that thermal fatigue micro-cracks initiate prior to oxidation, and the oxidation of cracked surface facilitate crack growth only $[1,2,28,29]$. In the present work, the steel surface was firstly oxidized and then oxide grew into the interior of matrix along the grain boundaries. It is observed that the initiation of thermal fatigue micro-cracks all occurred in the oxide region as demonstrated in Fig. 6. All the micro-cracks in HHD were formed in the center of oxide region (Fig. 6a). Micro-cracks in DIEVAR were found both in the center of the oxide region and at the interface between the oxide region and matrix steel 


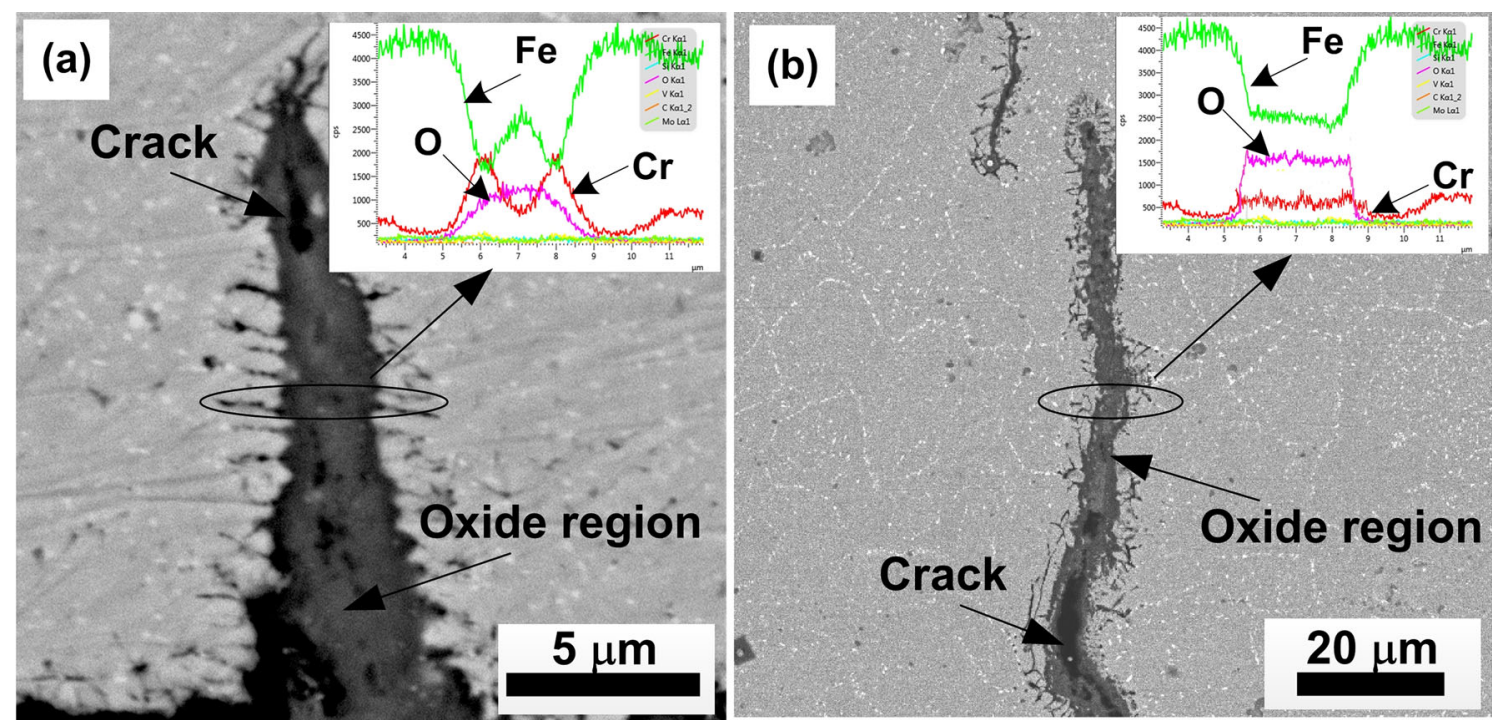

Fig. 5 SEM (back scattered electron) images and EDS spectra of the oxide cracks after 1000 cycles: a HHD; b DIEVAR
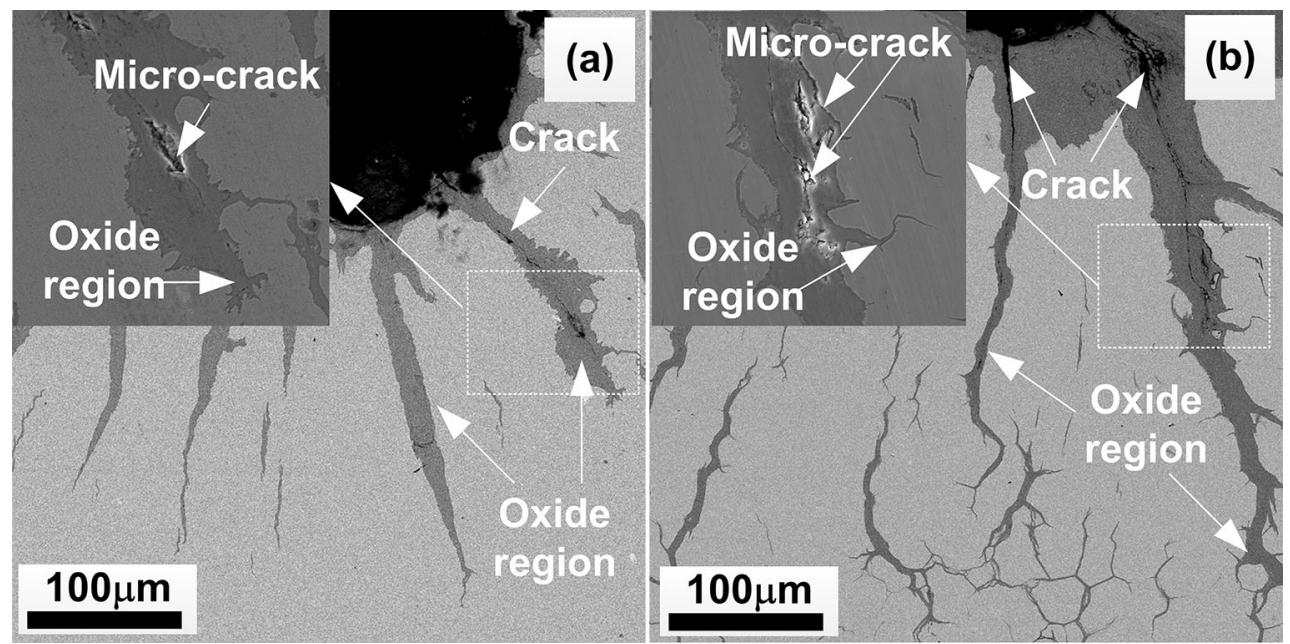

Fig. 6 SEM (back scattered electron) images of the oxide regions and cracks after 2000 cycles: a HHD; b DIEVAR

(Fig. 6b), which might be related to the composition of DIEVAR steel with higher $\mathrm{C}$ and lower $\mathrm{Cr}$ content. The difference in the thermal expansion coefficient and elastic modulus of the oxide and matrix steel induces thermal mismatch stress, which was concentrated in the oxide regions according to Eshelby's method [32]. The oxide region consists of fragile iron oxide mainly, and thus, oxide is easier to crack under the thermal mismatch stress, leading to the initiation of micro-cracks within the oxide region. The interface between the oxide layer and the steel matrix is also prone to cracks due to thermal mismatch stress [11]. As a result, a considerable amount of microcracks were formed along the oxide layer. During thermal fatigue testing, the macro-cracks were firstly formed in the oxide layers around the notch in both HHD and DIEVAR steel. The micro-cracks in the oxide region grew and connected to adjacent micro-cracks, leading to the propagation of the macro-cracks from the surface into the interior of matrix along the grain boundary oxide regions. Therefore, oxidation plays a crucial role in the thermal fatigue behavior.

\section{Conclusion}

The present work demonstrates an oxidation-induced formation mechanism of thermal fatigue cracks. Micro-cracks initiate in the oxidation region, and coalesce into a macrocrack, leading to the propagation of the macro-cracks along the oxide region. Therefore, high-temperature oxidation behavior is crucial for thermal fatigue crack formation in hot-work die steel, while high-temperature yield strength 
and ductility play a less important role. HHD steel exhibits superior thermal fatigue resistance to DIEVAR steel, which is attributed to its excellent oxidation resistance.

Acknowledgments This work was supported by the Project 985-High Properties Materials of Jilin University.

\section{References}

[1] D. Mellouli, N. Haddar, A. Köster, H.F. Ayedi, Eng. Fail. Anal. 20, 137 (2012)

[2] D. Klobčar, L. Kosec, B. Kosec, J. Tušek, Eng. Fail. Anal. 20, 43 (2012)

[3] J. Zhou, D.S Ma, H.X Chi, Z.Z Chen and X.Y Li. J. Iron Steel Res. Int. 20, 117 (2013)

[4] A. Persson, S. Hogmark, J. Bergström, Surf. Coat. Technol. 191, $216(2005)$

[5] C.M. Starling, J.R. Branco, Thin Solid Films 308, 436 (1997)

[6] A. Persson, S. Hogmark, J. Bergström, J. Mater. Process. Technol. 152, 228 (2004)

[7] I. Khader, A. Renz, A. Kailer, D. Haas, J. Eur. Ceram. Soc. 33, 593 (2013)

[8] B.K. Kosec, L. Kosec, J. Kopač, Eng. Fail. Anal. 8, 355 (2001)

[9] S. Malm, L.-A. Norström, Met. Sci. 13, 544 (1979)

[10] L.-Å. Norström, M. Svensson, N. Öhrberg, Met. Technol. 8, 376 (1981)

[11] Q.C. Jiang, H.L. Sui, Q.F. Guan, ISIJ Int. 44, 1103 (2004)

[12] A. Sherman, R. Davies, Int. J. Fatigue 3, 36 (1981)

[13] J. Sjöstrom, J. Bergström, J. Mater. Process. Technol. 153-154, $1089(2004)$
[14] X.F. Guo, Y.Y. Ni, J.M. Gong, Acta Metall. Sin. (Engl. Lett.) 30, 829 (2017)

[15] S.H. Sun, A.M. Zhao, R. Ding, Acta Metall. Sin. (Engl. Lett.) (in Press) https://doi.org/10.1007/s40195-017-0667-3

[16] X.L. Li, C.S. Lei, X.T. Deng, Acta Metall. Sin. (Engl. Lett.) 30, 1067 (2017)

[17] S. Kheirandish, A. Noorian, J. Iron Steel Res. Int. 15, 61 (2008)

[18] ̊̊. Gustafson, J. Ågren, Acta Mater. 46, 81 (1998)

[19] J.H. Park, Y.G. Kweon, H.J. Kim, I.B. Kim, ISIJ Int. 40, 1164 (2000)

[20] J. Gu, J. Li, Y. Chen, Metals 7, 310 (2017)

[21] Q.F. Guan, Q.C. Jiang, J.R. Fang, H. Jiang, ISIJ Int. 43, 784 (2003)

[22] H. Liu, P. Fu, H. Liu, C. Sun, J. Gao, D. Li, Metals 7, 436 (2017)

[23] Z. Wang, X. Chen, Y. Li, H. Zhang, Y. Liu, Acta Metall. Sin. 51, 519 (2015). (in Chinese)

[24] V. Leskovšek, B. Šuštaršič, G. Jutriša, J. Mater. Process. Technol. 178, 328 (2006)

[25] A. Ning, W. Mao, X. Chen, H. Guo, J. Guo, Metals 7, 70 (2017)

[26] Y. Zhang, J. Li, C.B. Shi, Y.F. Qi, Q.T. Zhu, Metals 7, 94 (2017)

[27] X.L. Gui, B.X. Zhang, G.H. Gao, P. Zhao, B.Z. Bai, Y.Q. Weng, Acta Metall. Sin. 52, 1036 (2016). (in Chinese)

[28] V.A. Kovrigin, B.S. Starokozhev, S.A. Yurasov, Met. Sci. Heat Treat. 22, 688 (1980)

[29] S. Chander, V. Chawla, Mater. Today Proc. 4, 1147 (2017)

[30] C. Xu, Q.L. Nai, Z.H. Yao, H. Jiang, J.X. Dong, Acta Metall. Sin. 53, 1453 (2017). (in Chinese)

[31] Q.H. Zhao, W. Liu, Y.C Zhu, Acta Metall. Sin. (Engl. Lett.) 30, 164 (2017)

[32] P.J. Withers, W.M. Stobbs, O.B. Pedersen, Acta Metall. 37, 3061 (1989) 